\title{
Development of New Carbon-Based Electrode Material from Oil Palm Waste-Derived Reduced Graphene Oxide and Its Capacitive Performance Evaluation
}

\author{
Salisu Nasir $\mathbb{D}^{1,},{ }^{1,2,3}$ Mohd Zobir Hussein $\mathbb{D}^{1},{ }^{1}$ Zulkarnain Zainal $\mathbb{D}^{3},{ }^{3}$ and Nor Azah Yusof $\mathbb{D}^{3}$ \\ ${ }^{1}$ Materials Synthesis and Characterisation Laboratory (MSCL), Institute of Advanced Technology (ITMA), \\ Universiti Putra Malaysia, 43400 Serdang, Selangor, Malaysia \\ ${ }^{2}$ Department of Chemistry, Faculty of Science, Federal University Dutse, 7156 Dutse, Jigawa State, Nigeria \\ ${ }^{3}$ Department of Chemistry, Faculty of Science, Universiti Putra Malaysia, 43400 Serdang, Selangor, Malaysia
}

Correspondence should be addressed to Salisu Nasir; salisunasirbbr@gmail.com and Mohd Zobir Hussein; mzobir@upm.edu.my

Received 24 April 2019; Revised 8 September 2019; Accepted 26 October 2019; Published 29 November 2019

Academic Editor: Renyun Zhang

Copyright (c) 2019 Salisu Nasir et al. This is an open access article distributed under the Creative Commons Attribution License, which permits unrestricted use, distribution, and reproduction in any medium, provided the original work is properly cited.

\begin{abstract}
This paper is an expansion of our previous work on the synthesis of graphene oxides and reduced graphene oxides from different kinds of oil palm waste-based feedstocks, namely, OPL (oil palm leaf), PKS (palm kernel shell), and EFB (empty fruit bunch). Here, the electrochemical measurements of the resulting reduced graphene oxides derived via mild-temperature annealing reduction of the graphene oxides were accomplished using cyclic voltammetry and galvanostatic charge/discharge processes. The findings put forward their promising features for supercapacitor applications. For instance, the reduced graphene oxide derived using EFB precursor (rGOEFB) which has a BET surface area of $117 \mathrm{~m}^{2} \mathrm{~g}^{-1}$ exhibits a specific capacitance of $688 \mathrm{Fg}^{-1}$ at an applied current density of $0.8 \mathrm{~A} \mathrm{~g}^{-1}$. This is higher than that observed for reduced graphene oxides derived from oil palm leaf (rGOOPL), palm kernel shell (rGOPKS), and the commercially acquired graphite (rGOCG), which possessed specific capacitance values of 632, 424 , and $220 \mathrm{Fg}^{-1}$, respectively. It can be deduced that the specific capacitance of the reduced graphene oxide samples increases in the following order: (rGOCG) $<($ rGOPKS $)<($ rGOOPL $)<($ rGOEFB $)$. In summary, these new classes of carbon-based nanomaterials could be applied as efficient electrode materials for supercapacitor application with potential good performance. With this novel green and sustainable approach, various carbon-based nanomaterials can be fabricated for a broad range of multifunctional applications.
\end{abstract}

\section{Introduction}

Energy sustainability and environmental threats as a result of climate change are among the major fears or problems facing humanity in the 21 st century [1-3]. Therefore, a change is ultimately needed to a more promising and reliable energy cycle based on renewable energy sources and environmentally friendly and nonpolluting ways of energy generation [4-7]. Undoubtedly, this is the only efficient way to curtail the production of fossil fuels and to eventually end their uses. It is very intriguing that electricity can be generated from emission-free sources now, for example, using nuclear reactors and solar cell panels, and can be stored in carbon-based supercapacitors, fuel cells, etc. The applica- tion of nanotechnology in the miniaturization of materials has significantly increased energy efficiency in the couple of decades [8].

Graphene or rather graphenoid/graphenic materials have since been used to improve the recharge time and capacity of ultracapacitors and lithium batteries [9-11]. However, the main challenge associated with renewable energy still remains an economical way of storing electricity in an adequate capacity that can take care of uninterrupted supply or in the case of transportation, to guaranty rapid recharge and dynamic availability after a vehicle has travelled some certain kilometers. Carbon nanotechnology, especially of graphene, its derivatives, and other graphitic carbon nanomaterials have been playing a considerable role in the 
advancement of high-performance supercapacitors [12]. Thus, these devices have shown strong potential to eliminate those constraints or drawbacks that have been encountered in the emerging electric vehicle technology. Therefore, the recent mass commercialization of carbon nanomaterials particularly graphene and carbon nanotube technologies could possibly replace the fossil-fuelled power stations proficiently by 2030 . This is believed to be achievable considering the astounding properties of carbon nanomaterials and their derivatives exhibited for electrochemical energy storage applications $[12,13]$. For instance, a one layer graphene sheet with a hypothetical surface area of $2630 \mathrm{~m}^{2} \mathrm{~g}^{-1}$ has been estimated to have a notional capacitance of $550 \mathrm{Fg}^{-1}[13,14]$.

Despite the fact that graphenic materials have since been used to improve the recharge time and capacity of ultracapacitors and lithium batteries, for example, holey graphene oxide was reported to exhibit ultrahigh capacitances of $283 \mathrm{Fg}^{-1}$ and $234 \mathrm{~F} / \mathrm{cm}^{3}$, and by integrating graphene with an inorganic $\mathrm{MnO}_{2}$, an enhanced capacitance of $1100 \mathrm{~F} / \mathrm{cm}^{3}$ has been achieved. However, to the best of the researchers' knowledge, this is the first time where oil palm waste-based graphitic carbons in the form of rGO were used in supercapacitor applications.

In a nutshell, by taking into account their abundance and sustainability prospects, oil palm-related wastes could be used widely as a cost-effective source of porous carbon materials for high-performance supercapacitors [15]. It is worth emphasizing that the combination of exceptional properties of graphene and its derivatives has undoubtedly played an integral role for new innovations across various industries such as automotive, wireless technology, energy, aerospace, 3D printing, coatings, consumer electronics, and therapeutics [8]. This has undoubtedly justified the quest for new and potential applications of carbon nanostructured materials such as the reduced graphene oxide (rGO) carbon nanotubes (CNT), carbon quantum dots (CQDs), and activated carbon (AC) produced from natural, renewable, and commonly available waste materials in recent years more especially in the electrochemical energy system or supercapacitor application.

Looking into the context of their technological application, electrical double layer capacitors (EDLCs) which are commonly known as ultracapacitors or supercapacitors are electrical energy storage devices with an excellent rechargeable quality [16]. These devices generally consist of high surface area electrodes engrossed in an electrolyte solution, which as a consequence enable the formation of an electrical double layer (EDL). The influence of the electrostatic force of attraction that occurs between the boundaries of the two substances triggers an electrical field to be instituted across the interface. Thus, within the layers of the EDLC, the mobile ions in the electrolyte solution are compelled to penetrate (via diffusion) into the pores of the high electrical conductive electrodes, and as a result, capacitances are generated. Captivatingly, due to their low series resistance, the EDLC performed as low impedance sources. This property paves the way for them to be charged and discharged more rapidly as compared to their counterpart (batteries). They have garnered substantial attention recently, especially in applica- tions where high power and low weight are especially important [17], and as a result, diminish the popularity of batteries $[18,19]$. This is occurring because the latter lack the capacity to give quick power disintegration, which is required for rapid charging-discharging applications. Secondly, its usable lifetime is generally impacted by the depth of discharge, length of time and voltage at maximum charge, rates of charging and discharging, and temperature. Other key disadvantages of most high power batteries include, but are not limited to, their short life span, requirement of a narrow temperature window to effectively operate, and above all no environmental benignity. In comparison to their counterpart, supercapacitors have more quick charge and discharge rates, as well as a higher energy storage capacity [18-20]. In contrast to conventional batteries, supercapacitors can endure low temperatures and offer long-cycle life and high efficiency (90\%) [14]. This made them suitable for peak power sources for an electric vehicle, mobile telecommunications, electronic devices, and back-up power storage [12], among others.

On the whole, reduced graphene oxide and graphene oxide produced by chemical oxidation of graphitic carbon formed from the pyrolysis of oil palm-related byproducts are attractive and very promising materials for energyrelated applications. In the context of this paper, the asproduced reduced graphene oxide has been used for supercapacitor electrodes based on its remarkable properties. As the first (oil palm waste-derived reduced graphene oxides) of its kind ever reported, the findings described in this present investigation could be considered as a baseline for further research on the potential valorization of byproduct materials from oil palm to graphenic-like materials for electrochemical energy storage applications. To sum it up, high-performance supercapacitor could be achieved by optimizing the specific surface area and controlling pore size distribution of the material. Nevertheless, it is important also to take into consideration the choice of the most suitable precursors, synthetic pathways, and conditions among others, in order to produce a carbon nanomaterial with an appropriate pore size tuned for the proficient electrode performance.

\section{Materials and Methods}

2.1. Materials. EFB (empty fruit bunch) and PKS (palm kernel shell) were donated by Seri Ulu Langat Palm Oil Mill, Dengkil, Selangor, while OPL (oil palm leaves) were picked at Taman Pertanian Universiti, Ladang 8, UPM. $\mathrm{H}_{2} \mathrm{SO}_{4}$ (98\%), $\mathrm{H}_{3} \mathrm{PO}_{4}(85 \%), \mathrm{HCl}(37 \%), \mathrm{KMnO}_{4}, \mathrm{H}_{2} \mathrm{O}_{2}$ (30\%), and ethanol (99.7\%) were purchased from SystermChemAR, Shah Alam, Malaysia, while graphite flakes were purchased from Sigma-Aldrich, St. Louis, MO, USA. All the chemicals were of analytical grade and used (as received) without further purification.

Even though there are several ways in which graphene and its derivatives can be fabricated, the most widely used in recent years are exfoliation of graphite [21] and chemical vapor deposition method [22]. Nevertheless, the reduction of graphene oxide $(\mathrm{GO})$ is also another viable approach of producing graphene-like materials (e.g., reduced graphene oxide) [23] in large quantity. In this work, initially, graphene 
oxide was prepared through the oxidation of graphite-like carbon powders (Figure 1) using the improved Hummers method [24]. Subsequently, the GO was then exfoliated in the reaction mixture through ultrasonication and then reduced via mild-temperature (thermal) reduction at $300^{\circ} \mathrm{C}$ in a furnace, producing a material with some features resembling graphene (i.e., processability and dispersibility) as reported in our previous work [1].

2.2. Structural Characterization. The FTIR (Fourier-transformed infrared) spectral measurement of the samples was done using a Thermo Nicolet, Nicolet 6700 models (Thermo Scientific, Waltham, MA, USA) with the KBr disc technique. The exterior surface morphology and microstructure of all of the prepared reduced graphene oxides were studied with a field emission scanning electron microscope (FESEM), an FEI Nova NanoSEM 230 (FEI, Hillsboro, OR, USA). The equipment is made up of dual operating modes that consist of high vacuum and low vacuum composition. It is designed to go with various forms of samples and could attain up to more than 500000x magnification. Before the analysis, small fractions of the desiccated samples were bestrewed on a conductive carbon adhesive tape surface that was rear-mounted to a FESEM end and then gold-coated using sputter coater. To examine the composition and structure of the samples, powder X-ray diffraction measurements were performed by way of a XRD-600 diffractometer (Shimadzu XRD-600, Tokyo, Japan), using $\mathrm{CuK}_{\alpha}$ radiation $(\lambda=0.15406 \mathrm{~nm})$. The operating voltage and current were retained at $30 \mathrm{kV}$ and $30 \mathrm{~mA}$, respectively, at a scanning rate of $4 \mathrm{~min}^{-1}$ and a range of 5 to $40^{\circ}(2 \theta)$. A Raman spectral analysis was made on a UHTS Alpha 300R Raman spectrometer (WITec GmbH, Ulm, Germany) at $532 \mathrm{~nm}$ (laser excitation wavelength) and an assimilation time of 5.03645 (s). The nitrogen adsorption-desorption isotherm evaluations were performed on a BELSORP Mini II (NIKKISO, Osaka, Japan) at $77 \mathrm{~K}$. The BET (Brunauer-Emmett-Teller) method was adopted to determine the specific surface area, while the pore size distribution was estimated using the BJH (Barrett-JoynerHalenda) method (which is based on capillary condensation theory, with presumption that the pore is cylindrically configured), and it was acquired using desorption data of a nitrogen adsorption isotherm. The total pore volume was evaluated from the quantity adsorbed at a relative pressure of $P / P_{o}=0.99$.

2.3. Electrochemical Tests. The electrochemical performance of the reduced graphene oxide samples was assessed by the cyclic voltammetry (CV) technique along with the galvanostatic charge and discharge profile measurements. The $\mathrm{CV}$ analyses were carried out at various scan rates: 5, 10, 50, 100 , and $200 \mathrm{mV} / \mathrm{s}$, in a neutral $1 \mathrm{M}$ potassium chloride electrolyte $(\mathrm{KCl})$. The voltammetric experiments and analysis were done with the help of $\mu$ Autolab Type III electrochemical analyzer equipment (PGSTAT204/FRA32M module, Eco Chemie, The Netherlands) attached to a workstation and controlled by General Purpose Electrochemical Systems software (Nova 1.11, Metrohm Autolab B.V., Utrecht, The Netherlands). All electrochemical-related tests were done in an electrochemical cell at ambient temperature. A conventional three electrode arrangement system was applied in the electrolyte solution. The glassy carbon electrode (GCE) coated with the as-produced reduced graphene oxide samples was used as the working electrode, while an $\mathrm{Ag} / \mathrm{AgCl}$ electrode served as the reference electrode, and a platinum electrode functioned as the supporting/counter electrode. It is important to point out that specific capacitance was measured from the galvanostatic charge/discharge (GCD) analysis. In this analysis, a constant current is applied to a given working electrode and the potential is measured with time. Thus, the potential transitional changes from the above scenario were used to calculate the specific capacitance using the equation as follows [13]:

$$
\mathrm{Csp}=\frac{I \times \Delta t}{\Delta V \times m}(\mathrm{~F} / \mathrm{g})
$$

where $I$ is a constant discharge current or current density $\left(\mathrm{A} \mathrm{g}^{-1}\right), \Delta t$ is the discharge time (s), $\Delta V$ is the voltage difference, and $m$ is the mass ( $g$ ) of the reduced graphene oxide sample encrusted on the glassy carbon electrode (GCE).

2.4. Preparation of the Glassy Carbon Working Electrode Surfaces. The working electrode is made up of the oil palm waste-derived reduced graphene oxides coated on a glassy carbon electrode by the drop cast technique using a micropipette. The optimum coating process was realized by way of ultrasonication of $0.01 \mathrm{~g}$ of the sample in $10 \mathrm{~mL}$ of deionized water for 35 minutes [25]. Ten (10) $\mu \mathrm{L}$ (equivalent to $0.00001 \mathrm{~g}$ ) droplet of the evenly dispersed (sonicated) reduced graphene oxide sample was instantly pipette and dispensed on the centre of the GCE. The modified electrode was then oven-dried at $35^{\circ} \mathrm{C}$ for $2 \mathrm{~h}$. The resulting modified electrodes/samples were abbreviated as rGOEFB-E1, rGOPKS-E2, rGOOPL-E3, and rGOCG-E4, respectively, for easy identification.

\section{Results and Discussion}

The reduced graphene oxides prepared in the present study (derived from oil palm byproduct materials) were subjected to various characterizations, and their electrochemical energy storage potentials were investigated. The findings are articulated and discussed below.

3.1. Fourier-Transformed Infrared (FTIR) Spectroscopy Analysis. The FTIR studies were carried out to examine the remaining functional groups, mostly the oxygen-related groups after the thermal reduction of the graphene oxides to reduced graphene oxides. Specific surface functional groups on both graphene oxide and reduced graphene oxide surfaces were revealed by the FTIR spectra according to the peculiarity of absorbed energy for each bond in certain groups. Thus, the FTIR spectra of graphene oxides before and after reduction are presented in Figure 2. All the spectra exhibit analogous absorption bonds, but with a shifting degree of intensity.

FTIR spectra of the graphene oxides (Figure 2(a)) exhibit a broad absorption peak of $v_{\mathrm{O}-\mathrm{H}}$ at $3437 \mathrm{~cm}^{-1}$ as a result of 


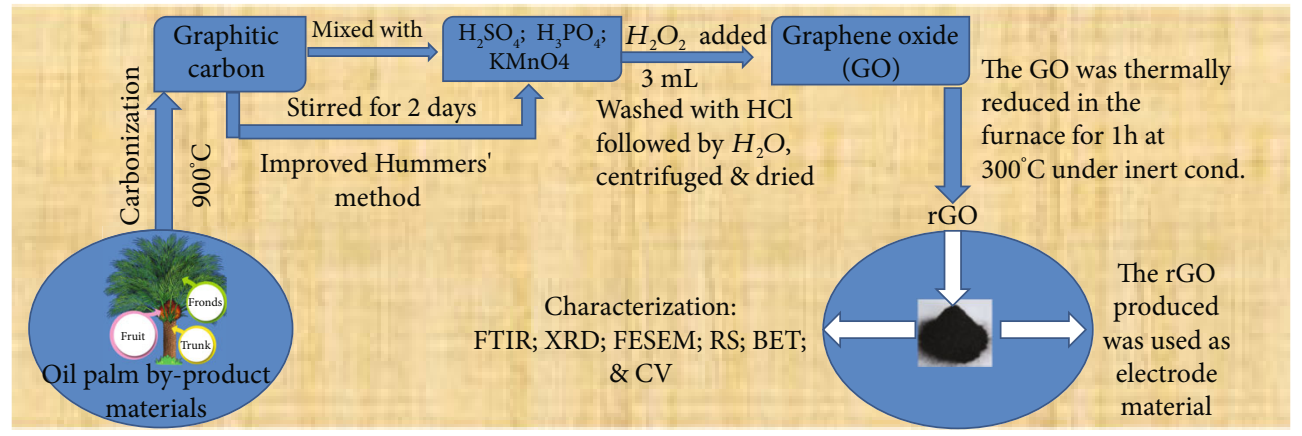

FIGURE 1: The synthetic pathways for the fabrication of reduced graphene oxide from oil palm waste-derived precursors coupled with its application as carbon-based electrode material for electrochemical energy storage application.

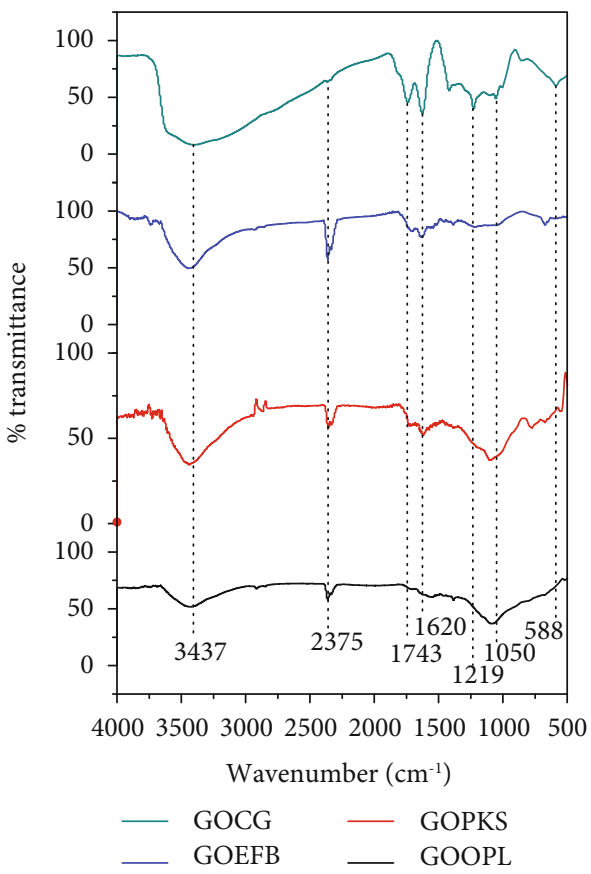

(a)

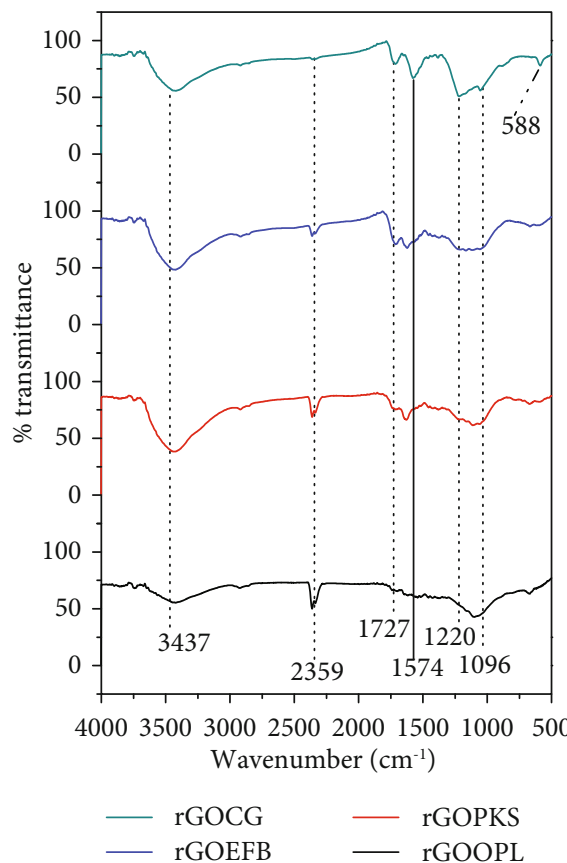

(b)

FIGURE 2: Fourier-transformed infrared spectra of oil palm waste-derived (a) graphene oxides and (b) reduced graphene oxides.

stretching vibration [26]. The organic acid $(\mathrm{COOH})$ groups at the edges of graphene oxide layers exhibit stretching vibration, and the $v_{\mathrm{C}=\mathrm{O}}$ peak emerged at $1743 \mathrm{~cm}^{-1}$. The spectra also reveal numerous characteristic peaks of graphene oxides, for instance, the $v_{\mathrm{C}=\mathrm{C}}$ at $1620 \mathrm{~cm}^{-1}$ owed to the aromatic $\mathrm{sp}^{2}$ $\mathrm{C}=\mathrm{C}$ bonds; $v_{\mathrm{C}-\mathrm{O}}$ at $1219 \mathrm{~cm}^{-1}$ emerged as a result of epoxy C-O stretching vibration; and $v_{\mathrm{C}-\mathrm{O}}$ at $1050 \mathrm{~cm}^{-1}$ owed to alkoxy C-O stretching vibration [27, 28]. Impliedly, the occurrence of carboxyl, epoxy, alkoxy, and hydroxyl functional groups in the GO FTIR spectrum connotes successful oxidation. This is because increase of these groups on the surface of graphene oxide is a sign revealing that the surface enhancement or modification with acidic and oxidative chemical agents $\left(\mathrm{H}_{2} \mathrm{SO}_{4}, \mathrm{H}_{3} \mathrm{PO}_{4}, \mathrm{KMnO}_{4}\right.$, and $\left.\mathrm{H}_{2} \mathrm{O}_{2}\right)$ has occurred and developed the surface oxygen-containing groups during the GO formation.

The formation of reduced graphene oxide, on the other hand, is further attested by FTIR spectroscopy (Figure 2(b)).
Successful reduction (removal of oxygen functional groups) can be seen for reduced graphene oxides with the diminishing intensity of all the oxide functional groups. The bands become weaker due to the strong assimilation or absorption of the carbon materials (Figure 2(b)). However, a strong C-O band that surfaced from 1220 to $1096 \mathrm{~cm}^{-1}$ (yet after the GO has been reduced) may be ascribed to cyclic ether or oxygen atoms assembled at the edges of defects in reduced graphene oxide. From this, it can be deduced that all the oxygen groups are likely detached from the part contiguous to edges and only graphene domains are evident in the reduced material [29]. However, Si and Samulski have reported to observe no effect on the electronic trait of the reduced graphene oxide by the presence of oxygen moieties on its edges [30].

3.2. Field Emission Scanning Electron Microscopy. Figure 3 depicts the micrographs of reduced graphene oxide fabricated from various starting raw materials using the improved 


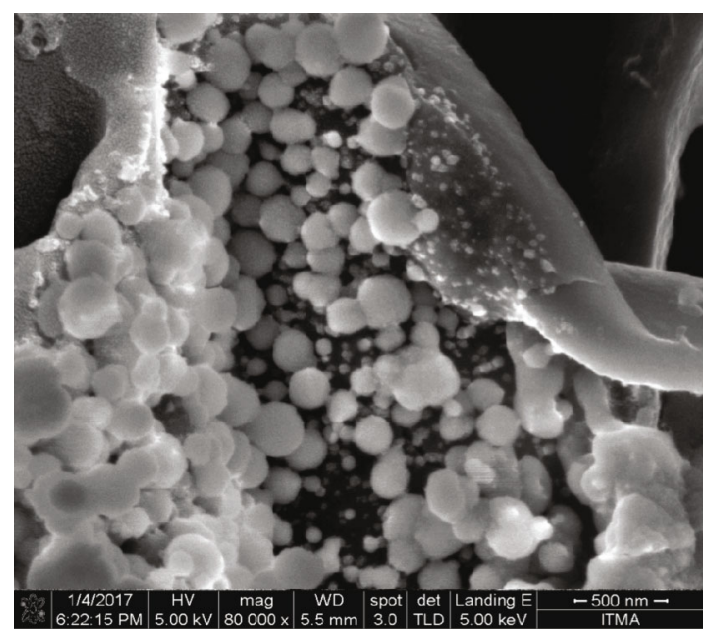

(a)

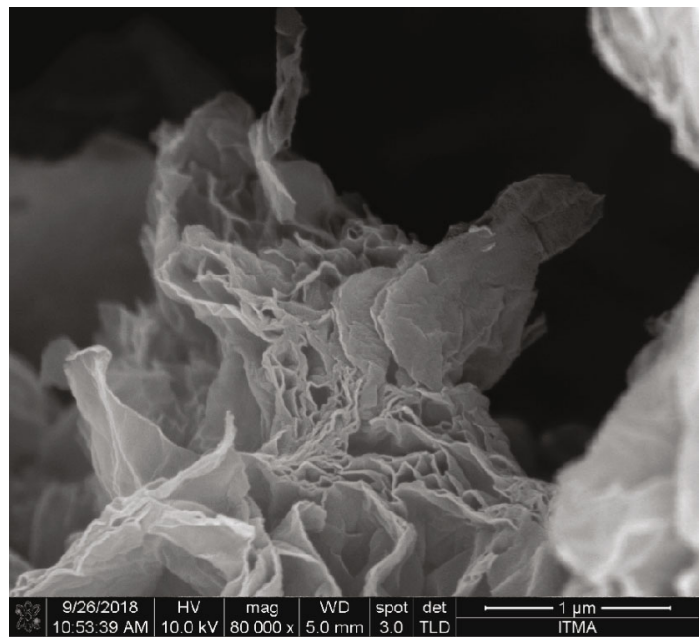

(c)

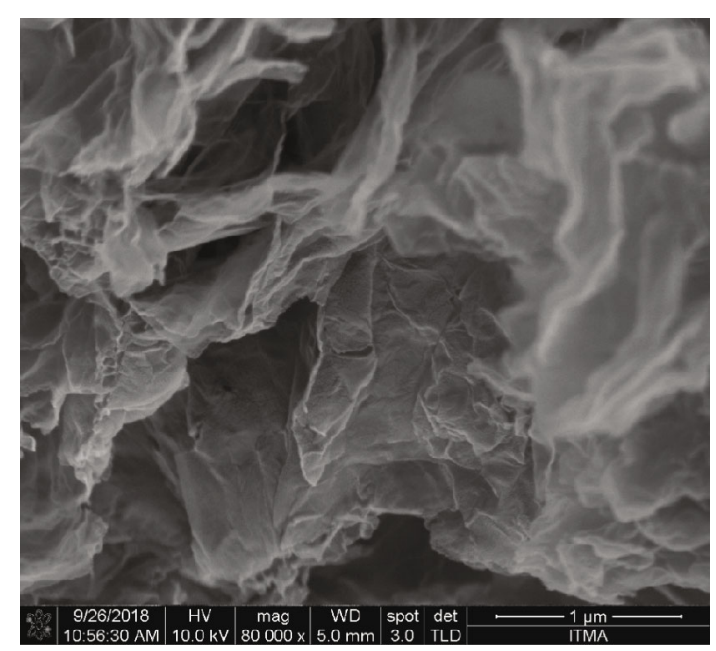

(b)

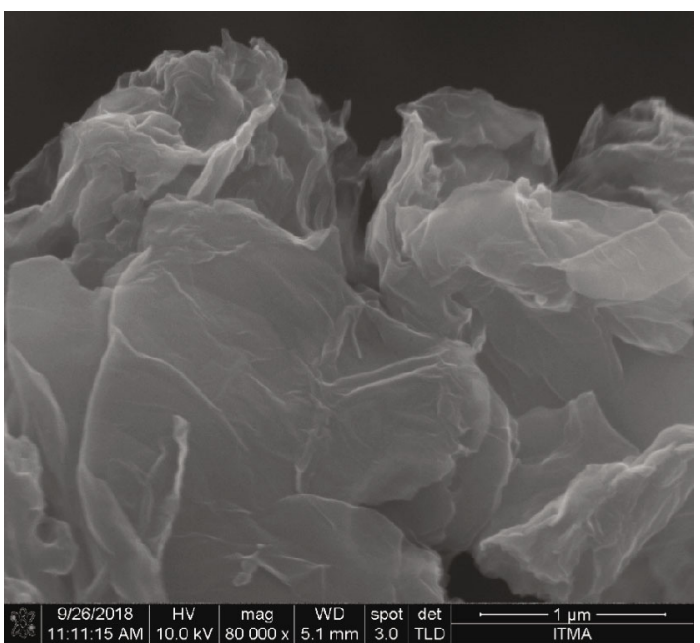

(d)

FIGURE 3: Field emission scanning electron microscopy (FESEM) images of the reduced graphene oxide (rGO) samples: (a) rGO derived from the oil palm leaf (rGOOPL) having a carbon matrix exhibiting a nanoball-like structure, (b) rGO derived from palm kernel shell (rGOPKS), (c) rGO derived from the empty fruit bunch (rGOEFB), and (d) rGO derived from commercial graphite (rGOCG).

method. Micrographs were captured with 80000x magnifications, respectively. As can be examined in Figure 3(a), the rGOOPL formed a nanoball-like structure and dispersed consistently within the rGOOPL carbon matrix. However, the formation of reduced graphene oxide with a flexible multilayered nanosheet-like structure can be observed for rGOPKS, rGOEFB, and rGOCG, respectively (Figures 3(b)-3(d)). Nonetheless, the rGOEFB demonstrated less of the corrugations as compared to its counterparts. In general, the wrinkles or corrugated morphologies of the thermally exfoliated reduced graphene oxides have been reported to be caused as a result of the thermodynamic stability of the 2D membrane emanating from microscopic rumpling through bending or buckling [31].

3.3. X-Ray Diffraction Analysis and Electrochemical Energy Storage Relationship. The summary of the XRD (X-ray diffraction) structural examination of the oil palm wastederived reduced graphene oxides is presented in Figure 4.
The XRD pattern of all of the samples confirmed the structure of pure carbon material. This was recognized by broad peaks at $2 \theta=23^{\circ}$ in the XRD pattern of all of the reduced graphene oxide samples which also match to the wellknown crystallographic planes (002) of carbon material. However, a trace of the GO peak at around $2 \theta=12^{\circ}$ which could be seen in the rGOCG sample (Figure $4(\mathrm{~d})$ ) indicates partial or incomplete reduction of the sample. The incomplete reduction of this sample (rGOCG) could be one of the reasons for its very low specific surface area $\left(8 \mathrm{~m}^{2} \mathrm{~g}^{-1}\right)$ and specific capacitance $\left(220 \mathrm{Fg}^{-1}\right.$, at $\left.0.8 \mathrm{Ag}^{-1}\right)$ as compared to the other reduced graphene oxide samples. In addition, this trace of graphene oxide peak, which may represent the content of oxygen in the material, has been reported as a strong driver for hydrophilicity, which in turn enhanced the wettability of the electrolyte. Unfortunately, this condition (oxygen content) is unfavorable for stability, electrical conductivity, and electrochemical capacity of the material [32]. This could presumably be another reason for the 


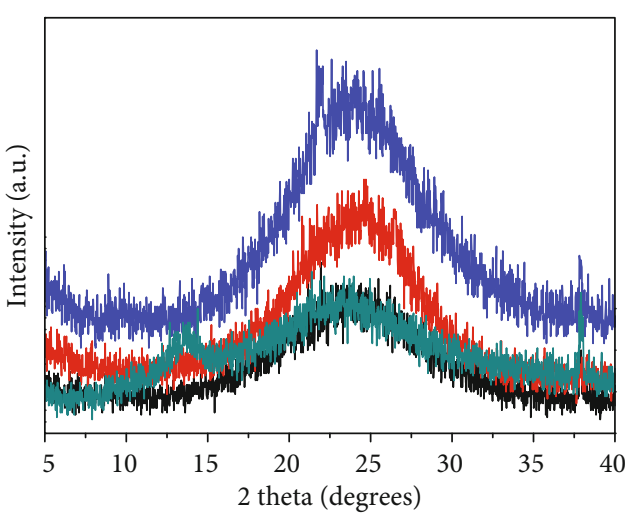
(a) rGOOPL
(c) rGOEFB
(b) rGOPKS
(d) rGOCG

Figure 4: Powder X-ray diffraction patterns of all of the reduced graphene oxide derived from the various precursors.

reduced electrochemical performance of the rGOCG-E4 sample as compared to the other samples.

3.4. Raman Spectral Analysis. Raman spectral analysis (RSA) was primarily done in order to characterize the as-prepared reduced graphene oxides which can be used to correlate the electrical properties of the as-modified reduced graphene oxide-based electrode with their structural changes. In this connection, the RSA of all of the reduced graphene oxides (Figure 5) illustrate strong $D$ and $G$ peaks, signifying very small crystal sizes [33]. Generally, structural information about the defect and the graphitic nature of the materials are determined using these parameters. The evolution of Raman D peak has been described as a defect arising from the disordering or imperfection of graphite, but ordering of carbon structures in amorphous materials [34], while the G band generally occurs due to in-plane bond stretching of pairs of $\mathrm{sp}^{2} \mathrm{C}$ atoms, and it becomes obvious at all $\mathrm{sp}^{2}$ sites and may not markedly be ascribed to the existence of a sixfold ring [33]. Thus, a very well-reduced GO is expected to be more ordered than the partially reduced one. For this reason, the $I_{\mathrm{G}} / I_{\mathrm{D}}$ value will increase with increasing orderliness in graphitic structures.

3.5. BET and $\mathrm{N}_{2}$ Adsorption/Desorption Isotherm Analyses. In order to swiftly assess the surface area and the pore size distributions after the reduced graphene oxides were synthesized, a nitrogen adsorption/desorption study was conducted and the isotherms were demonstrated in Figures 6 and 7, respectively. It has been observed that the isotherms of the rGOPKS and rGOEFB as shown in Figures 6(a) and 6(c) resemble the Type I (IUPAC) isotherm and signify that the materials are microporous solids containing or exhibiting relatively small external surfaces [35].

On the other hand, the isotherms of the rGOOPL and rGOCG displayed in Figures 7(a) and 7(c) resemble the Type H3-loop (IUPAC) isotherm [35] which is generally attributed to the presence of mesoporosity. The filling/emptying of those pores (mesopores) has been reported as the main driver that influences the appearance of hysteresis of any

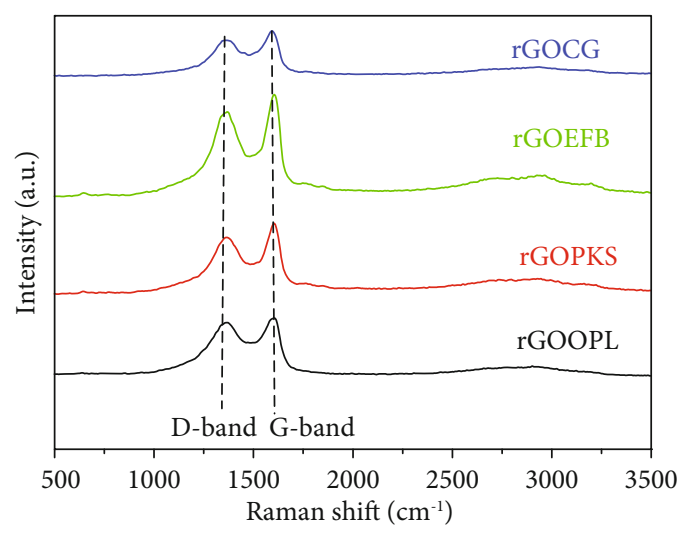

FIgURE 5: Raman spectral analyses of all of the reduced graphene oxide samples derived from oil palm wastes, indicating $\mathrm{D}$ $\left(\sim 1340 \mathrm{~cm}^{-1}\right)$ and $\mathrm{G}\left(\sim 1590 \mathrm{~cm}^{-1}\right)$ bands.

type. Thus, the hysteresis emerging in the multilayer range of physisorption isotherms is openly ascribed with capillary condensation in the mesopore structures and in some cases could have numerous types of shapes [35]. The alleged condensation process is a systematic phenomenon that occurs in those pores and extends up to the point when the pores are fully occupied by the condensable vapor at high relative pressure. However, when the relative pressure gradually reduces, the liquid tends to leave the pores by way of the constricted necks. These phenomenon progresses at a lower relative pressure than what was needed for filling the pores, and once the critical relative pressure is attained, the pores unfilled immediately. And this paves the way for the loop in the isotherms to be formed.

As explicated in Table 1, the rGOOPL exhibited an average mesopore diameter of $14 \mathrm{~nm}$. These wider mesopores require more pressure to be filled completely which is connected to the fact that multilayer adsorption emerges on low energy locations (uni-/bilayer) far-off from the wall. Thus, the main or maximum nitrogen adsorption/desorption occurs at the high pressure section, and as a result, the hysteresis move near high $P / P_{o}$ regions (at $P / P_{o} \sim 0.8$ ) as revealed in Figure $7(\mathrm{a})$. On the other hand, the H3-loop isotherm of rGOCG is marked with a sharp step-down of the desorption branch situated in a constricted range of $P / P_{o}(\sim 0.5)$ for adsorptive $\mathrm{N}_{2}$ at $77 \mathrm{~K}$ (Figure $7(\mathrm{c})$ ).

It is noteworthy that one of the important determinants that influence capacitance of the capacitor is the porosity or the extent of pore size distribution of the carbon material. Thus, a facilitated ion diffusion throughout the charge and discharge processes (which is directly proportional to good capacitive performance) has been widely experimented and reveals to be caused by the pores of the carbon-based materials. For this reason, materials with excellent pore size distribution not only have been given attention but also are always needed for higher capacitive performance. This owed to the fact that good pore size distribution of the carbon material acts as a powerful driver for better ion diffusion between the electrodes to electrolyte interface in electrochemical energy storage applications [32]. Thus, according 


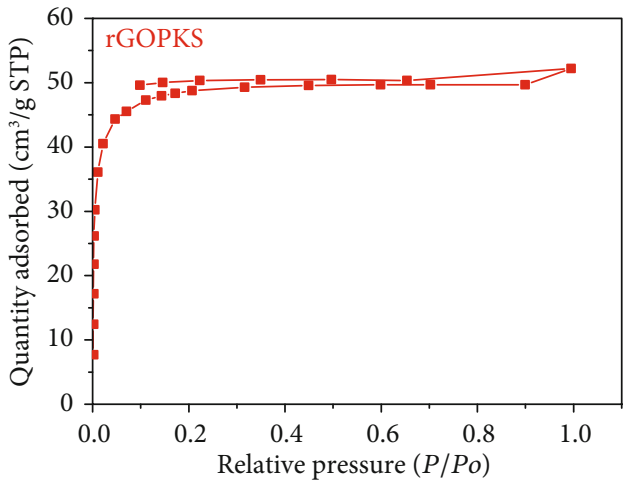

(a)

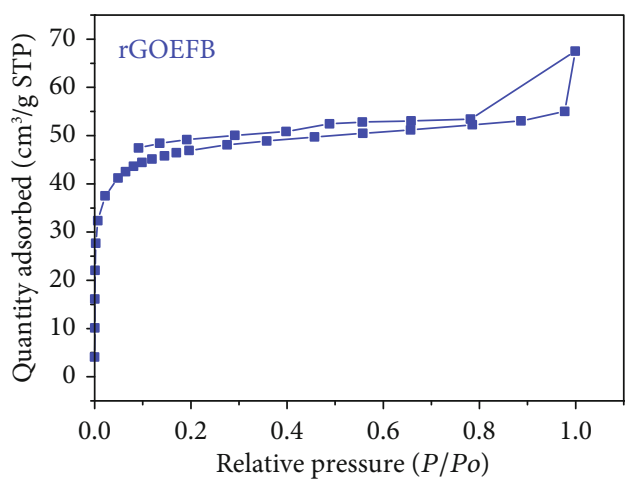

(c)

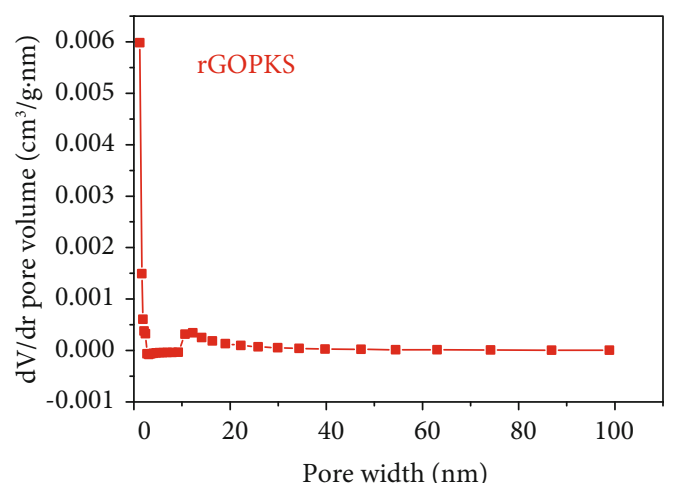

(b)

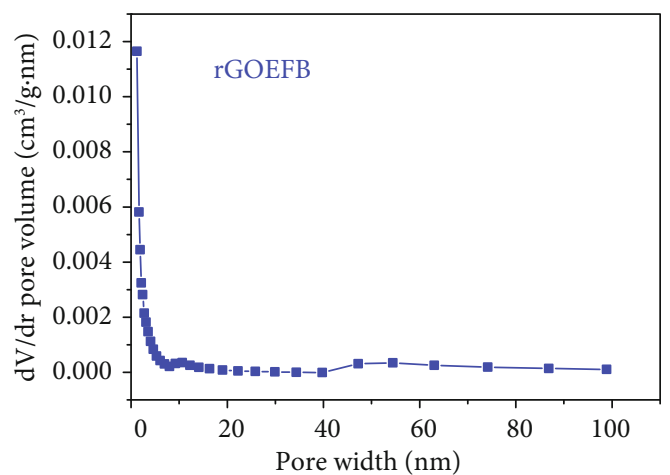

(d)

FIGURE 6: The nitrogen adsorption-desorption isotherms and pore size distribution of rGOPKS ( $a$ and b, respectively) and rGOEFB (c and d, respectively).

to this present finding, rGOEFB exhibited superior capacitive performance as compared to its counterparts, rGOOPL, rGOPKS, and rGOCG (Table 1), due to its porous/porosity disposition as marked from the gas adsorption isotherms (Figures 6(c) and 6(d)). These porous structures are believed to be essentially suitable for electrochemical reactions, given that they facilitate appropriate dissemination of the electrolyte into the core of the electrochemical materials [10].

In a nutshell, the BET surface area of the rGOEFB sample $\left(117 \mathrm{~m}^{2} \mathrm{~g}^{-1}\right)$ and an average pore diameter of $3 \mathrm{~nm}$ (evaluated using the $\mathrm{BJH}$ method) could be the main reason for the high specific capacitance of this sample.

It has been observed within the biomass-based rGO samples (rGOEFB, rGOPKS, and rGOOPL) that a relatively higher BET surface area is recorded for the sample with correspondingly slightly higher graphitic content as evident from the $I_{\mathrm{G}} / I_{\mathrm{D}}$ ratio (Table 1 ). The trend is also nearly similar for specific capacitance obtained from these materials. Therefore, it can be presumed that high capacitive performance (within these samples) could be directly linked to the graphitic content and surface area (in some cases) of the material. Those trends or tendencies demonstrated by the as-produced materials emphasized the remarkable benefit of using sustainable and cost-effective substances to fabricate new carbon-based materials for electrochemical energy storage application. In this light, the research (investigated materials) could be integrated into the global paradigm shift towards sustainable development.
In spite of the fact that the reduced graphene oxide carbon particles facilitate better ion diffusion between the electrode-electrolyte interfaces, the lower surface area and moderate specific capacitance of rGOCG samples (Table 1) occurred due to the multiple heaping of reduced graphene oxide layers and nearby-obstructed pores. These drawbacks generally transpire as a consequence of powerful pi to pi stacking connections and van der Waals interactions between the planar basal planes of reduced graphene oxide layers or sheets and has been reported to significantly reduce the surface area of the reduced graphene oxide $[13,36]$. For this reason, it is always exigent to fabricate highly conductive graphene exhibiting a very high surface area from graphene oxide [36]. In summary, the propensity of rGOCG to restack themselves during fabrication and consequent electrode development has been inferred to impede the accessibility of the electrolyte into the intergraphene pore sizes and the formation of electrical double layer (EDL) charges. Thus, it is always imperative to take into consideration the pore accessibility and surface compatibility of graphene by the electrolyte for this type of applications [14].

3.6. Cyclic Voltammetry (CV) and Galvanostatic Charge/Discharge (GCD) Profiles. By way of CV, qualitative information on electrochemical reactions can generally be acquired without difficulty. The uniqueness of the technique gives not only swift identification of the location of the redox potentials of the electroactive species but also practical 


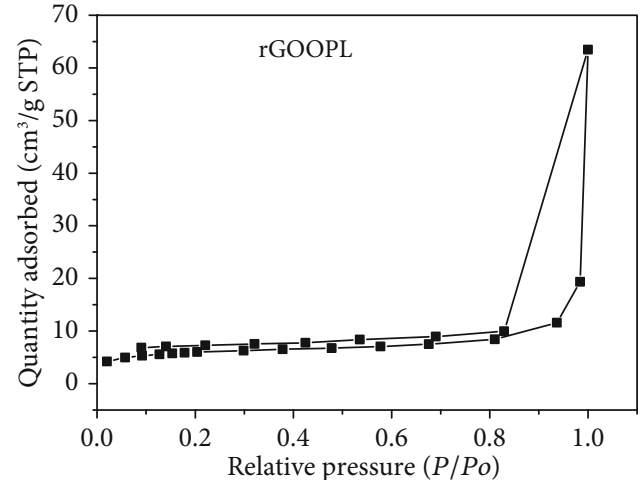

(a)

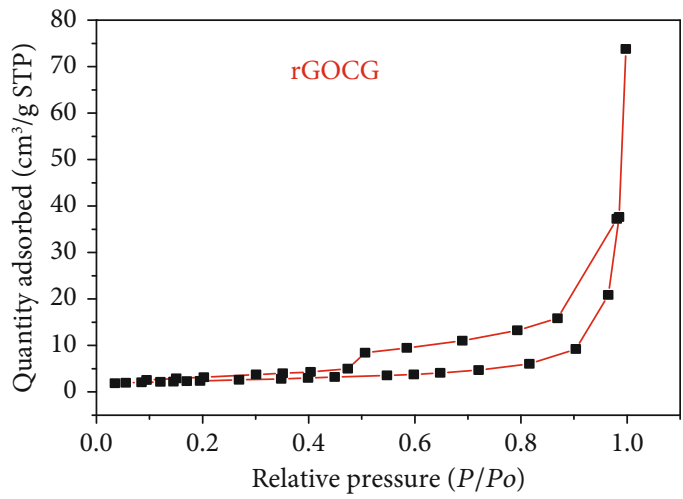

(c)

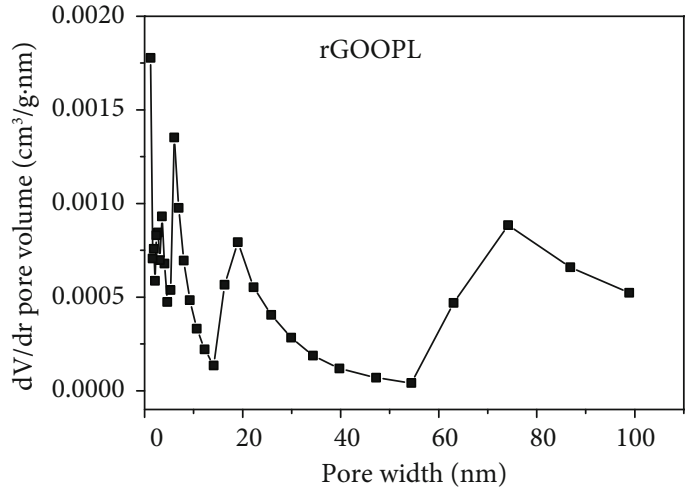

(b)

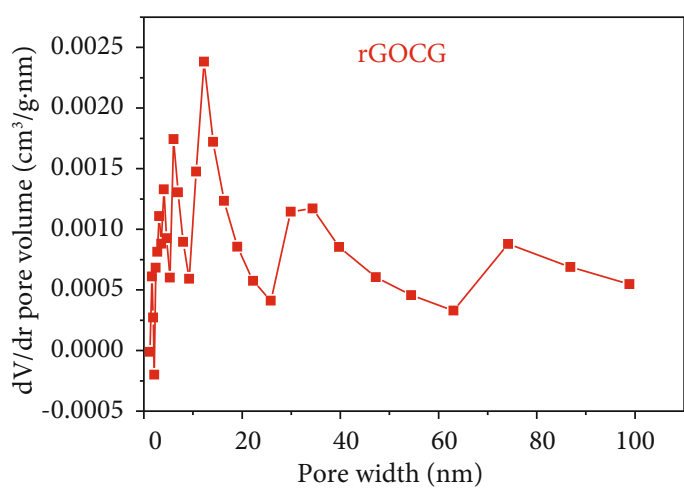

(d)

FIGURE 7: The nitrogen adsorption-desorption isotherms and pore size distribution of rGOOPL ( $a$ and b, respectively) and rGOCG (c and d, respectively).

TABLE 1: A summary of the graphitic trait, BET surface area, average pore diameter, and the corresponding specific capacitance value (measured at $0.8 \mathrm{~A} \mathrm{~g}^{-1}$ ) of the as-prepared reduced graphene oxide samples.

\begin{tabular}{lccccc}
\hline $\begin{array}{l}\text { rGO } \\
\text { samples }\end{array}$ & $\begin{array}{c}I_{\mathrm{G}} / I_{\mathrm{D}} \\
\text { ratios }\end{array}$ & $\begin{array}{c}\text { Surface } \\
\text { area } \\
\left(\mathrm{m}^{2} \mathrm{~g}^{-1}\right)\end{array}$ & $\begin{array}{c}\text { Average } \\
\text { pore } \\
\text { diameter } \\
(\mathrm{nm})\end{array}$ & $\begin{array}{c}\text { Total pore } \\
\text { volume } \\
\left(\mathrm{cm}^{3} \mathrm{~g}^{-1}\right)\end{array}$ & $\begin{array}{c}\text { Specific } \\
\text { capacitance } \\
\left(\mathrm{F} \mathrm{g}^{-1}\right) \text { at } \\
0.8 \mathrm{Ag}^{-1}\end{array}$ \\
\hline rGOOPL & 1.16 & 15 & 14 & 0.06 & 632 \\
rGOPKS & 1.14 & 114 & 3 & 0.08 & 424 \\
rGOEFB & 1.20 & 117 & 3 & 0.10 & 688 \\
rGOCG & 1.06 & 8 & 41 & 0.08 & 220 \\
\hline
\end{tabular}

assessment of the influence of media on the redox process [37]. This involves and enables measurement of the equivalent current of the electrochemical redox reaction (with precision) when the potential is scanned. It is noteworthy that the values obtained for both the voltages and the current during the analysis generally depend on the analyte concentration (Nernst equation) and the kinetic diffusion properties (Fick's law).

Applying this technique (Figures $8(a)-8(d)$ ) to the capacitance-elucidation/measurement has great potential for the advancement of our conception of fundamental processes and for the future of energy storage research. Consequently, the galvanostatic charge/discharge (GCD) evaluations were done within the potential window of $-0.2 \mathrm{~V}$ to $+1 \mathrm{~V}$ at different current densities from 0.8 to $3 \mathrm{~A} \mathrm{~g}^{-1}$. This test was performed essentially to assess the electrical capacitance efficiency of the reduced graphene oxide samples. The comparative GCD curves of all the materials are given in Figures 8(b), 8(d), 9(b), and 9(d), respectively. The resulting charge and discharge curves at high current densities ( 2 and $3 \mathrm{Ag}^{-1}$ ) exhibited triangular shapes, in addition to exhibiting linear discharge characteristics, indicative of the capacitive behavior of the supercapacitor cell or good EDL performance [14]. The specific capacitance was calculated using Equation (1) as described earlier, and the results were plotted and enclosed in Figures 10(a) and 10(b). Captivatingly, the charging curve exhibited a close symmetry with the resulting discharge curve; thus, the linear voltage-time correlation could signify the practical capacitive efficiency of the rGOEFB-E1 sample.

According to the GCD measurements (Figures 8(b), 8(d), 9(b), and 9(d), respectively), the discharging time of rGOEFBE1 and rGOOPL-E3 is moderately much longer than that of rGOPKS-E2 and rGOCG-E4. Thus, at both low current density $\left(0.8 \mathrm{~A} \mathrm{~g}^{-1}\right)$ and higher current density $\left(3 \mathrm{Ag}^{-1}\right)$, there 


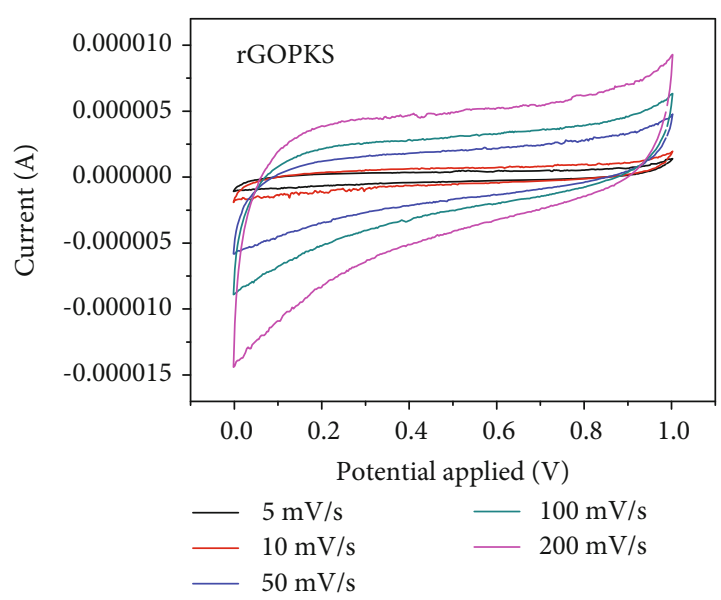

(a)

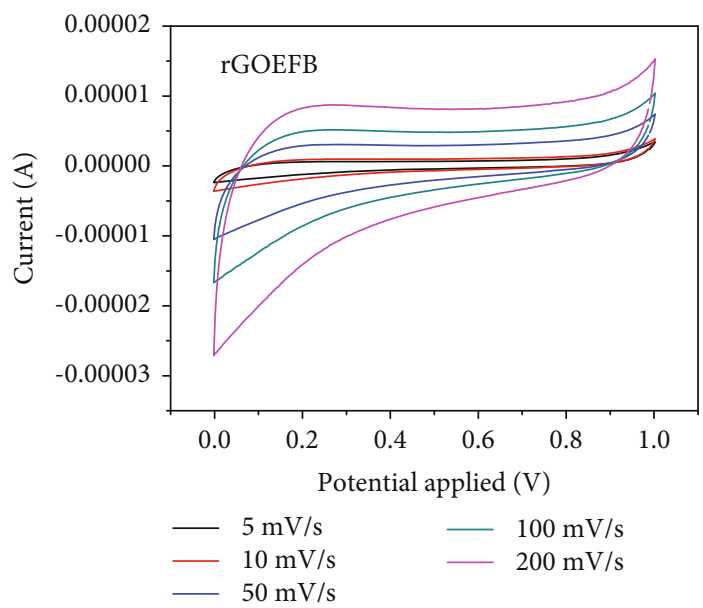

(c)

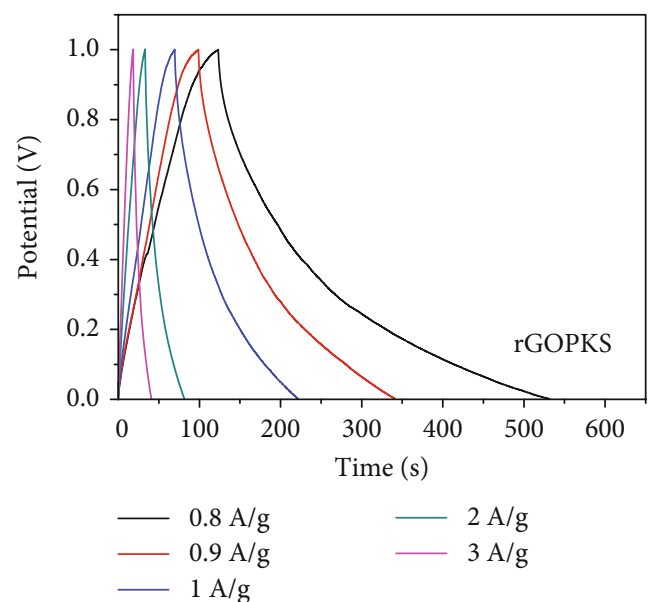

(b)

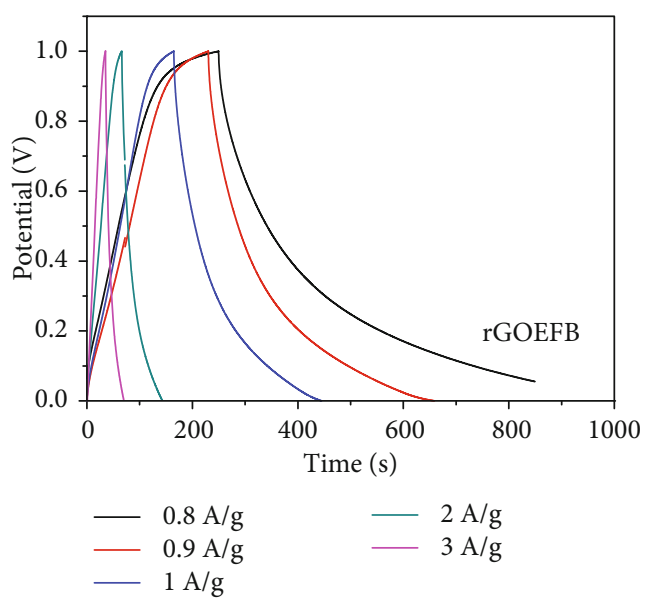

(d)

FIGURE 8: Electrochemical studies for the rGOPKS-E2 and rGOEFB-E1 electrodes: (a, c) cyclic voltammetry curves measured at various scan rates in $\mathrm{mV} / \mathrm{s}$ and $(\mathrm{b}, \mathrm{d})$ galvanostatic charge/discharge curves determined at various current densities in $\mathrm{A} \mathrm{g}^{-1}$.

is a clear variation in the specific capacitance among the whole samples (Table 2).

The galvanostatic charge/discharge measurement of new samples (rGOOPL and rGOPKS; prepared using the method described earlier) was further taken at current densities of 1 , $2,3,4$, and $5 \mathrm{Ag}^{-1}$, respectively. This was done to ascertain how the accuracy of the procedure was maintained. Based on the new specific capacitance $\left(260\right.$ and $365 \mathrm{Fg}^{-1}$, respectively) obtained at $1 \mathrm{~A} \mathrm{~g}^{-1}$ from these samples (Figure 10), it is inferred that the results are in close agreements with the previous ones. For comparison purpose, a plot of specific capacitance $\left(\mathrm{Fg}^{-1}\right)$ versus current densities in $\mathrm{A} \mathrm{g}^{-1}$ and a plot of BET surface area $\left(\mathrm{m}^{2} \mathrm{~g}^{-1}\right)$ of all of the reduced graphene oxide samples against specific capacitance of all of the materials measured at $0.8 \mathrm{~A} \mathrm{~g}^{-1}$ were given in Figure 11 .

Cycling performance is one of the fundamental features of electrode material that determines its real life application for supercapacitors. For this reason, cyclic stability evaluation of the rGOEFB-E1 electrode was carried out at a relatively high GCD constant current of $7 \mathrm{~mA}$ over 1000 cycles. As demonstrated in Figure 12(a), i.e., specific capacitance $\left(\mathrm{Fg}^{-1}\right)$ as a function of number of cycles, it can be described that about $91 \%$ of the initial specific capacitance was retained even after 1000 cycles. Based on the stability of the rGOEFB-E1 under this extreme cycling condition, it is deduced that the material could be used effectively in supercapacitor applications.

To further assess the electrochemical behavior of the materials for supercapacitor application, an electrochemical impedance spectroscopy (EIS) measurement was performed at the electrode-electrolyte interface. As shown in Figure 12(b), the Nyquist plots were incorporated to elucidate the electrochemical impedance of the supercapacitor cells. All the plots encompass two different parts which comprise of an arc in the high frequency region and a nearly vertical line in the low frequency region. It has been reported that the linear impedance curve adjacent to the imaginary impedance axis $\left(-Z^{\prime \prime}\right)$ in the lower frequency region of the Nyquist plots indicates capacitance features of the reduced graphene oxide sample [13, 38], which is in good agreement with this work (Figure 12(b)). The nearly small curve in the higher frequency region of the rGOEFB-E1 electrode (Figure 12(b) inset) correlates with the electrode-electrolyte interface resistance in the supercapacitor system [39-41]. Similarly, this small semicircle diameter 


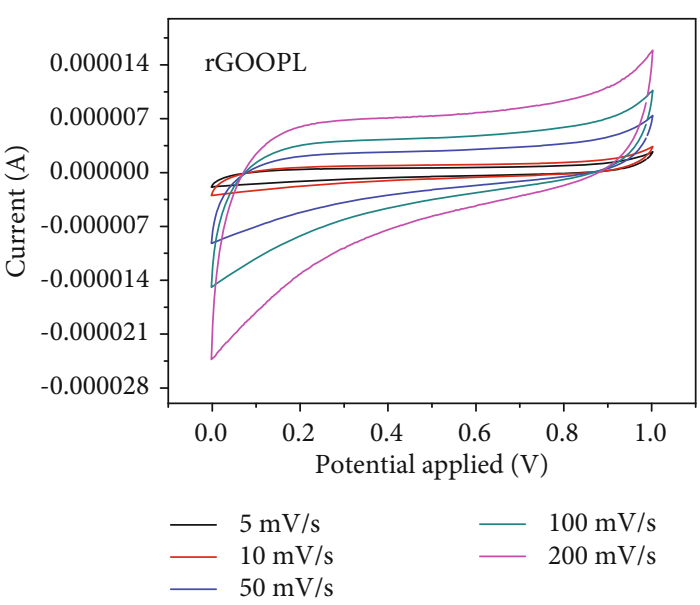

(a)

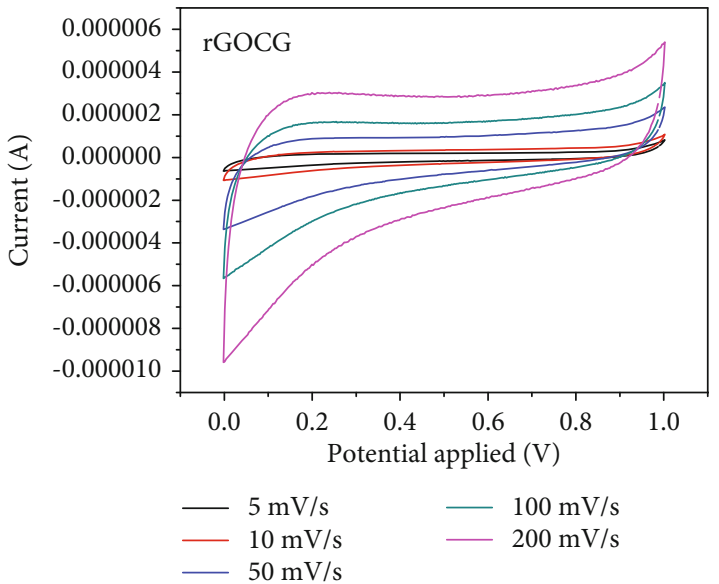

(c)

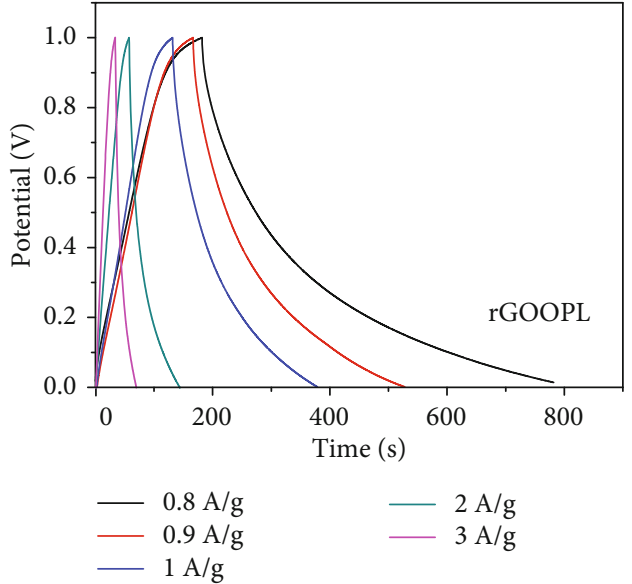

(b)

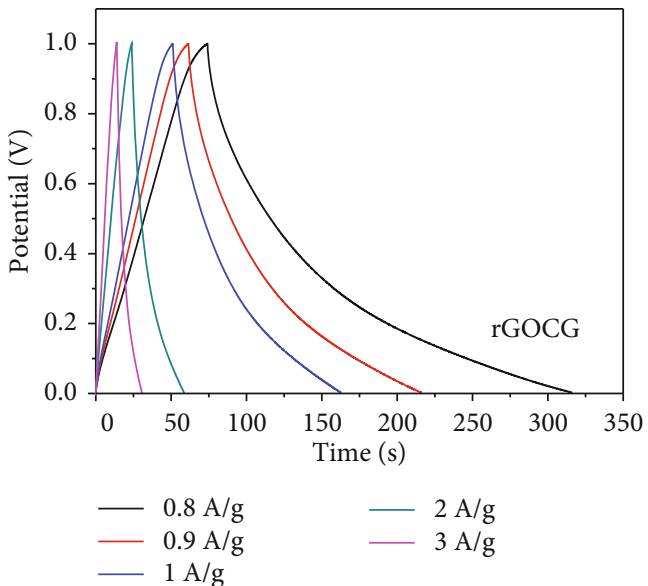

(d)

FIGURE 9: Electrochemical studies for the rGOOPL-E3 and rGOCG-E4 electrodes: (a, c) cyclic voltammetry curves measured at various scan rates in $\mathrm{mV} / \mathrm{s}$ and $(\mathrm{b}, \mathrm{d})$ galvanostatic charge/discharge curves determined at different current densities in $\mathrm{A} \mathrm{g}^{-1}$.

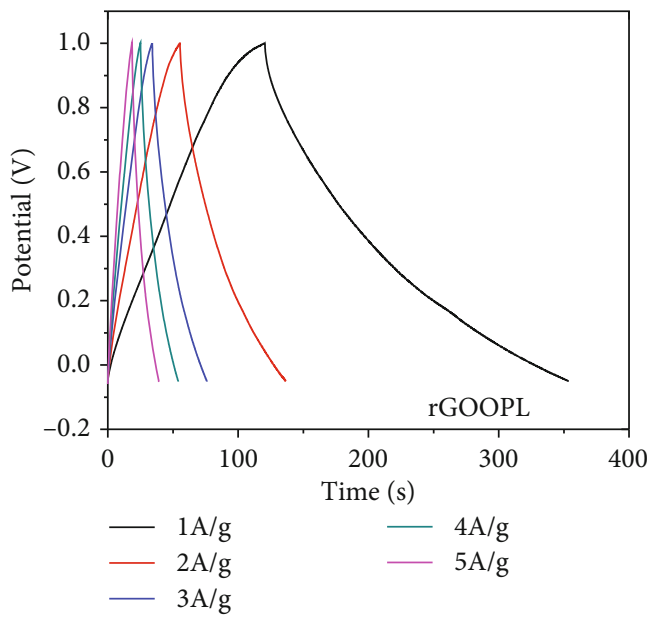

(a)
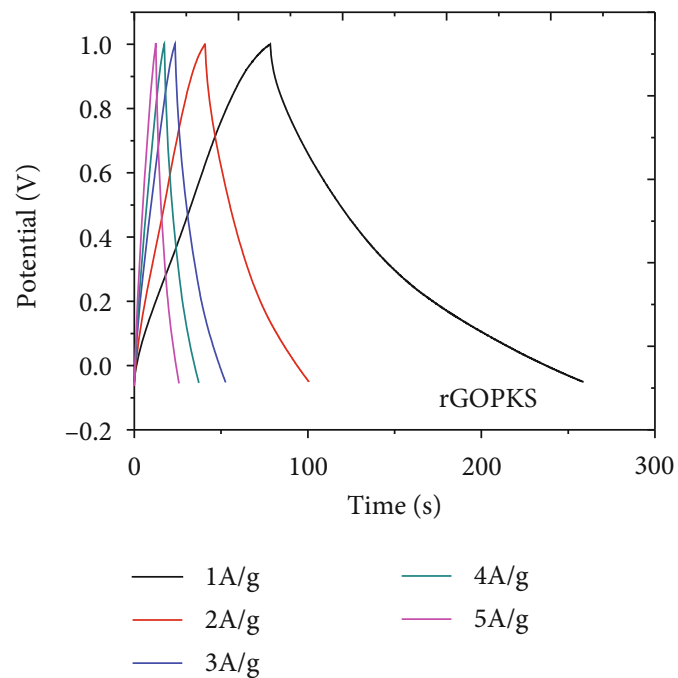

(b)

Figure 10: Galvanostatic charge/discharge curves of (a) rGOOPL and (b) rGOPKS determined at new current densities of 1, 2, 3, 4, and 5 A g ${ }^{-1}$. 
TABLE 2: The specific capacitance of the as-prepared reduced graphene oxide electrodes measured in $\mathrm{Fg}^{-1}$ from the GCD at various current densities.

\begin{tabular}{lcccc}
\hline $\begin{array}{l}\text { Current densities } \\
\left(\mathrm{Ag}^{-1}\right)\end{array}$ & $\begin{array}{c}\text { rGOCG-E4 capacitance } \\
\text { values }\left(\mathrm{Fg}^{-1}\right)\end{array}$ & $\begin{array}{c}\text { rGOOPL-E3 capacitance } \\
\text { values }\left(\mathrm{Fg}^{-1}\right)\end{array}$ & $\begin{array}{c}\text { rGOPKS-E2 capacitance } \\
\text { values }\left(\mathrm{Fg}^{-1}\right)\end{array}$ & $\begin{array}{c}\text { rGOEFB-E1 capacitance } \\
\left.\text { values }(\mathrm{Fg})^{-1}\right)\end{array}$ \\
\hline 0.8 & 220 & 632 & 424 & 688 \\
0.9 & 171 & 459 & 315 & 558 \\
1.0 & 145 & 380 & 225 & 420 \\
2.0 & 104 & 260 & 180 & 280 \\
3.0 & 81 & 240 & 147 & 240 \\
\hline
\end{tabular}

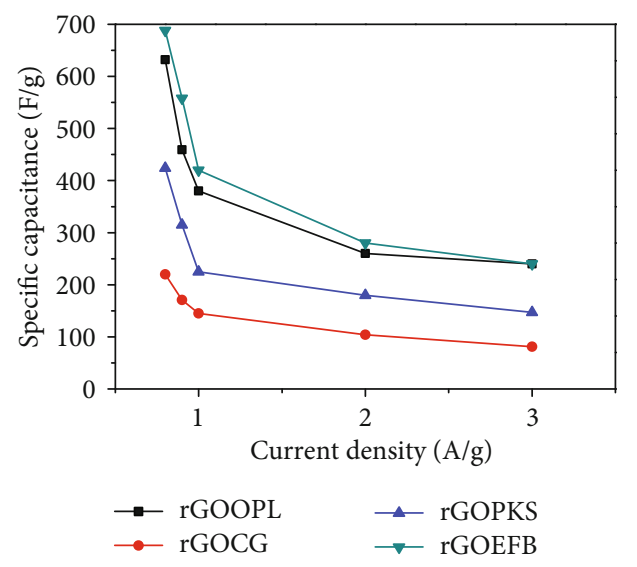

(a)

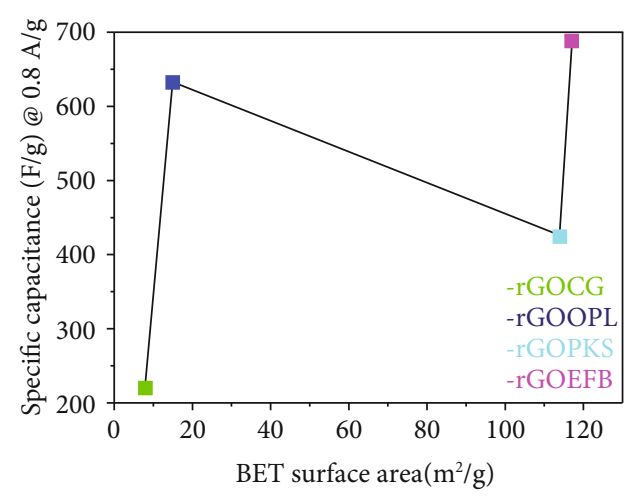

(b)

Figure 11: (a) Plot of specific capacitance $\left(\mathrm{Fg}^{-1}\right)$ versus current densities in $\mathrm{A} \mathrm{g}^{-1}$ and (b) plot of BET surface area $\left(\mathrm{m}^{2} \mathrm{~g}^{-1}\right)$ of all of the reduced graphene oxide samples against specific capacitance of all of the materials measured at $0.8 \mathrm{~A} \mathrm{~g}^{-1}$.

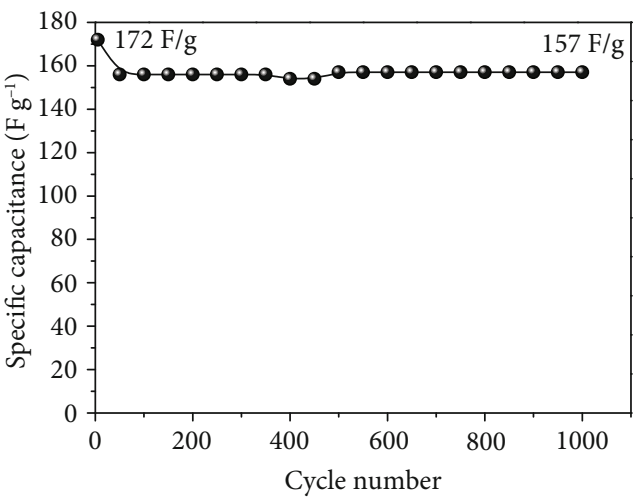

(a)

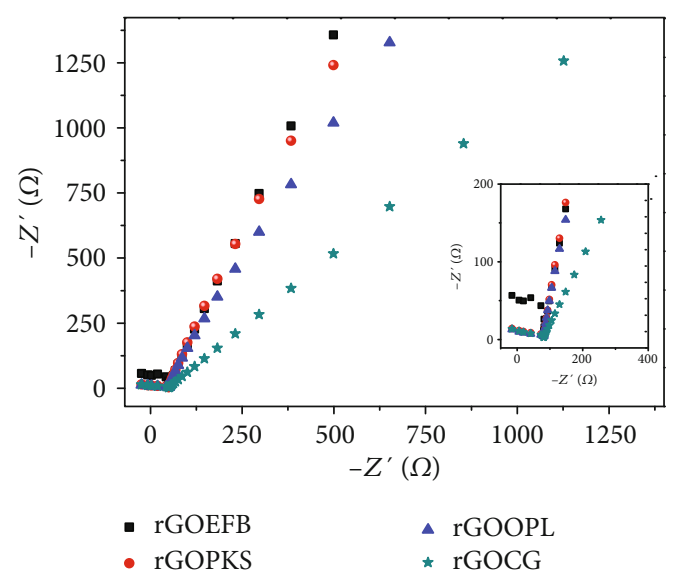

(b)

Figure 12: (a) Specific capacitance versus cycle number for the rGOEFB-E1 electrode at GCD current density of $7 \times 10^{-6} \mathrm{Ag}^{-1}$; (b) Nyquist plots of all the reduced graphene oxide electrodes using the sinusoidal signal of $10 \mathrm{mV}$ over the frequency range from $0.01 \mathrm{~Hz}$ to $1 \mathrm{mHz}$. The inset represents their magnified dimension in the higher frequency region. The real impedance is marked as $Z^{\prime}$ while the imaginary impedance as $Z^{\prime \prime}$.

of rGOEFB-E1 also indicates total electrode resistance, attributable to its nearly equivalent ratio of micropore and mesopore volume [42] $\left(0.10 \mathrm{~cm}^{3} / \mathrm{g}\right)$, which is believed to be the reason of its superior specific capacitance. This owed to the better penetration of the electrolyte ions into the inner pores of this sample as compared to its counterparts, which on the other hand have lesser total pore volumes as formerly shown in Table 1. 


\section{Conclusions}

On the whole, this paper investigated the electrochemical energy storage outlook of reduced graphene oxides derived from various oil palm waste-based precursors. It has been inferred that the reduced graphene oxide sample resulting from empty fruit bunch precursor (rGOEFB) exhibits higher electrochemical capacitance of $688 \mathrm{Fg}^{-1}$ at $0.8 \mathrm{Ag}^{-1}$ (with better charge storage properties) than that prepared using oil palm leaf (rGOOPL), palm kernel shell (rGOPKS), and even the commercially acquired graphite (rGOCG) which was primarily used as a control. This superior capacitive value exhibited by rGOEFB as compared to its counterparts is attributed to its moderate specific surface area $\left(117 \mathrm{~m}^{2} \mathrm{~g}^{-1}\right)$, average pore diameter $(3 \mathrm{~nm})$, and total pore volume of $0.10 \mathrm{~cm}^{3} / \mathrm{g}$. Nevertheless, the performance (specific capacitance) of this electrode material could be immensely improved through the coating with metal oxides or conductive polymers to institute pseudocapacitance. Thus, further study should explore these possibilities. Equally important, the fabrication pathway of the material has an influential role in deciding the traits of the as-fabricated material, as it dictates surface or edge activities as well as charge carrier dynamics via structure and composition manipulations. On the whole, by taking into account their abundance and renewability potentials, oil palm waste-based precursors could be used as the new biomass source for the carbon-based electrode for supercapacitor application. In effect, this not only could offer a sustainable and cost-effective replacement possibility of other materials in the production of reduced graphene oxide as the supercapacitor electrode but also will help in solving the existing charging problem encountered in the emerging new electric vehicle technology.

\section{Data Availability}

Data used to support the findings of this study are available from the corresponding authors upon request.

\section{Conflicts of Interest}

The authors declare no conflict of interest.

\section{Authors' Contributions}

S.N. and M.Z.H. worked on conceptualization. M.Z.H. and Z.Z. took part in the data curation. S.N. did the formal analysis, investigation, methodology, and writing-original draft. M.Z.H. and N.A.Y. handled funding acquisition. M.Z.H., Z.Z., and N.A.Y. participated in the project administration, supervision, and editing. M.Z.H. managed resources.

\section{Acknowledgments}

Salisu Nasir would like to thank the Federal University Dutse, Nigeria, for his Ph.D. study leave. This work was supported by the Universiti Putra Malaysia and the Ministry of Higher Education of Malaysia under the Putra grant, GP-IPS/2018/9627200. The APC was funded by UPM.

\section{References}

[1] S. Nasir, M. Hussein, N. Yusof, and Z. Zainal, "Oil palm wastebased precursors as a renewable and economical carbon sources for the preparation of reduced graphene oxide from graphene oxide," Nanomaterials, vol. 7, no. 7, 2017.

[2] D. A. King, "Environment: climate change science: adapt, mitigate, or ignore?," Science, vol. 303, no. 5655, pp. 176-177, 2004.

[3] B. Moyo, D. Momodu, O. Fasakin, A. Bello, J. Dangbegnon, and N. Manyala, "Electrochemical analysis of nanoporous carbons derived from activation of polypyrrole for stable supercapacitors," Journal of Materials Science, vol. 53, no. 7, pp. 5229-5241, 2018.

[4] M.-M. Titirici, R. J. White, N. Brun et al., "Sustainable carbon materials," Chemical Society Reviews, vol. 44, no. 1, pp. 250 290, 2015.

[5] J. Deng, M. Li, and Y. Wang, "Biomass-derived carbon: synthesis and applications in energy storage and conversion," Green Chemistry, vol. 18, no. 18, pp. 4824-4854, 2016.

[6] P. Kalyani and A. Anitha, "Biomass carbon \& its prospects in electrochemical energy systems," International Journal of Hydrogen Energy, vol. 38, no. 10, pp. 4034-4045, 2013.

[7] F. O. Ochai-Ejeh, A. Bello, J. Dangbegnon et al., "High electrochemical performance of hierarchical porous activated carbon derived from lightweight cork (Quercus suber)," Journal of Materials Science, vol. 52, no. 17, pp. 10600-10613, 2017.

[8] S. Nasir, M. Hussein, Z. Zainal, and N. Yusof, "Carbon-based nanomaterials/allotropes: a glimpse of their synthesis, properties and some applications," Materials, vol. 11, no. 2, 2018.

[9] A. Ambrosi, C. K. Chua, A. Bonanni, and M. Pumera, "Electrochemistry of graphene and related materials," Chemical Reviews, vol. 114, no. 14, pp. 7150-7188, 2014.

[10] H. Kim, K.-Y. Park, J. Hong, and K. Kang, "All-graphene-battery: bridging the gap between supercapacitors and lithium ion batteries," Scientific Reports, vol. 4, no. 1, article 5278, 2015.

[11] Y. Zhu, S. Murali, M. D. Stoller et al., "Carbon-based supercapacitors produced by activation of graphene," Science, vol. 332, no. 6037, pp. 1537-1541, 2011.

[12] T. Chen and L. Dai, "Carbon nanomaterials for highperformance supercapacitors," Materials Today, vol. 16, no. 7-8, pp. 272-280, 2013.

[13] A. Ramesh, M. Jeyavelan, and M. S. Leo Hudson, "Electrochemical properties of reduced graphene oxide derived through camphor assisted combustion of graphite oxide," Dalton Transactions, vol. 47, no. 15, pp. 5406-5414, 2018.

[14] C. Liu, Z. Yu, D. Neff, A. Zhamu, and B. Z. Jang, "Graphenebased supercapacitor with an ultrahigh energy density," Nano Letters, vol. 10, no. 12, pp. 4863-4868, 2010.

[15] S. Nasir, M. Z. Hussein, Z. Zainal, N. A. Yusof, S. A. M. Zobir, and I. M. Alibe, "Potential valorization of by-product materials from oil palm: a review of alternative and sustainable carbon sources for carbon-based nanomaterials synthesis," BioResources, vol. 14, no. 1, pp. 2352-2388, 2019.

[16] A. Srivastava and B. SanthiBhushan, "Trade-off between quantum capacitance and thermodynamic stability of defected graphene: an implication for supercapacitor electrodes," Applied Nanoscience, vol. 8, no. 4, pp. 637-644, 2018.

[17] Y. Zhang, S. Yu, G. Lou et al., "Review of macroporous materials as electrochemical supercapacitor electrodes," Journal of Materials Science, vol. 52, no. 19, pp. 11201-11228, 2017. 
[18] E. Frackowiak and F. Béguin, "Carbon materials for the electrochemical storage of energy in capacitors," Carbon, vol. 39, no. 6, pp. 937-950, 2001.

[19] H. Liu, Y. Zhang, Q. Ke, K. H. Ho, Y. Hu, and J. Wang, "Tuning the porous texture and specific surface area of nanoporous carbons for supercapacitor electrodes by adjusting the hydrothermal synthesis temperature," Journal of Materials Chemistry A, vol. 1, no. 41, pp. 12962-12970, 2013.

[20] I. A. Khan, A. Badshah, A. A. Altaf, N. Tahir, N. Haider, and M. A. Nadeem, "Acid base co-crystal converted into porous carbon material for energy storage devices," RSC Advances, vol. 5, no. 12, pp. 9110-9115, 2015.

[21] S. Stankovich, D. A. Dikin, R. D. Piner et al., "Synthesis of graphene-based nanosheets via chemical reduction of exfoliated graphite oxide," Carbon, vol. 45, no. 7, pp. 1558-1565, 2007.

[22] S. Sharma, G. Kalita, R. Hirano et al., "Synthesis of graphene crystals from solid waste plastic by chemical vapor deposition," Carbon, vol. 72, pp. 66-73, 2014.

[23] S. Pei and H. M. Cheng, "The reduction of graphene oxide," Carbon, vol. 50, no. 9, pp. 3210-3228, 2012.

[24] D. C. Marcano, D. V. Kosynkin, J. M. Berlin et al., "Improved synthesis of graphene oxide," ACS Nano, vol. 4, no. 8, pp. 4806-4814, 2010.

[25] S. Nasir, M. Hussein, Z. Zainal, N. Yusof, and S. Mohd Zobir, "Electrochemical energy storage potentials of waste biomass: oil palm leaf- and palm kernel shell-derived activated carbons," Energies, vol. 11, no. 12, p. 3410, 2018.

[26] S. A. Sharief, R. A. Susantyoko, M. Alhashem, and S. Almheiri, "Synthesis of few-layer graphene-like sheets from carbonbased powders via electrochemical exfoliation, using carbon black as an example," Journal of Materials Science, vol. 52, no. 18, pp. 11004-11013, 2017.

[27] M. Wojtoniszak, X. Chen, R. J. Kalenczuk et al., "Synthesis, dispersion, and cytocompatibility of graphene oxide and reduced graphene oxide," Colloids and Surfaces B: Biointerfaces, vol. 89, no. 1, pp. 79-85, 2012.

[28] K. Muthoosamy, R. Geetha Bai, I. B. Abubakar et al., "Exceedingly biocompatible and thin-layered reduced graphene oxide nanosheets using an eco-friendly mushroom extract strategy," International Journal of Nanomedicine, vol. 10, pp. 1505-1519, 2015.

[29] M. Acik, G. Lee, C. Mattevi, M. Chhowalla, K. Cho, and Y. J. Chabal, "Unusual infrared-absorption mechanism in thermally reduced graphene oxide," Nature Materials, vol. 9, no. 10 , pp. $840-845,2010$.

[30] Y. Si and E. T. Samulski, "Synthesis of water soluble graphene," Nano Letters, vol. 8, no. 6, pp. 1679-1682, 2008.

[31] R. P. Antony, L. K. Preethi, B. Gupta, T. Mathews, S. Dash, and A. K. Tyagi, "Efficient electrocatalytic performance of thermally exfoliated reduced graphene oxide-Pt hybrid," Materials Research Bulletin, vol. 70, pp. 60-67, 2015.

[32] X. Zhao, M. Li, H. Dong et al., "Interconnected 3 D network of graphene-oxide nanosheets decorated with carbon dots for high-performance supercapacitors," ChemSusChem, vol. 10, no. 12, pp. 2626-2634, 2017.

[33] C. Y. Su, Y. Xu, W. Zhang et al., "Highly efficient restoration of graphitic structure in graphene oxide using alcohol vapors," ACS Nano, vol. 4, no. 9, pp. 5285-5292, 2010.

[34] A. C. Ferrari, "Raman spectroscopy of graphene and graphite: disorder, electron-phonon coupling, doping and nonadiabatic effects," Solid State Communications, vol. 143, no. 1-2, pp. 4757, 2007.

[35] K. S. W. Sing, "Reporting physisorption data for gas/solid systems with special reference to the determination of surface area and porosity (provisional)," Pure and Applied Chemistry, vol. 54, no. 11, pp. 2201-2218, 1982.

[36] K. H. Kim, M. H. Yang, K. M. Cho, Y.-S. Jun, S. B. Lee, and H.-T. Jung, "High quality reduced graphene oxide through repairing with multi-layered graphene ball nanostructures," Scientific Reports, vol. 3, no. 1, article 3251, 2013.

[37] J. Wang, Analytical Electrochemistry, John Wiley \& Sons, Inc., Publication, New York, USA, Second edition, 2000.

[38] Y.-Q. Dang, S.-Z. Ren, G. Liu, J. Cai, Y. Zhang, and J. Qiu, "Electrochemical and capacitive properties of carbon dots/reduced graphene oxide supercapacitors," Nanomaterials, vol. 6 , no. 11, p. 212, 2016.

[39] A. M. Abioye, Z. A. Noorden, and F. N. Ani, "Synthesis and characterizations of electroless oil palm shell based-activated carbon/nickel oxide nanocomposite electrodes for supercapacitor applications," Electrochimica Acta, vol. 225, pp. 493502, 2017.

[40] F. Barzegar, A. Bello, D. Momodu, M. J. Madito, J. Dangbegnon, and N. Manyala, "Preparation and characterization of porous carbon from expanded graphite for high energy density supercapacitor in aqueous electrolyte," Journal of Power Sources, vol. 309, pp. 245-253, 2016.

[41] R. Bhujel, S. Rai, and B. P. Swain, "Investigation of cyclic voltammetry, impedance spectroscopy and electrical properties of thermally exfoliated biomass-synthesized graphene," Applied Nanoscience, vol. 9, no. 6, pp. 1319-1331, 2019.

[42] C. K. Sim, S. R. Majid, and N. Z. Mahmood, "Electrochemical performance of activated carbon derived from treated foodwaste," International Journal of Electrochemical Science, vol. 10, no. 12, pp. 10157-10172, 2015. 


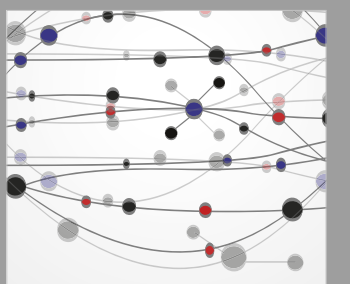

The Scientific World Journal
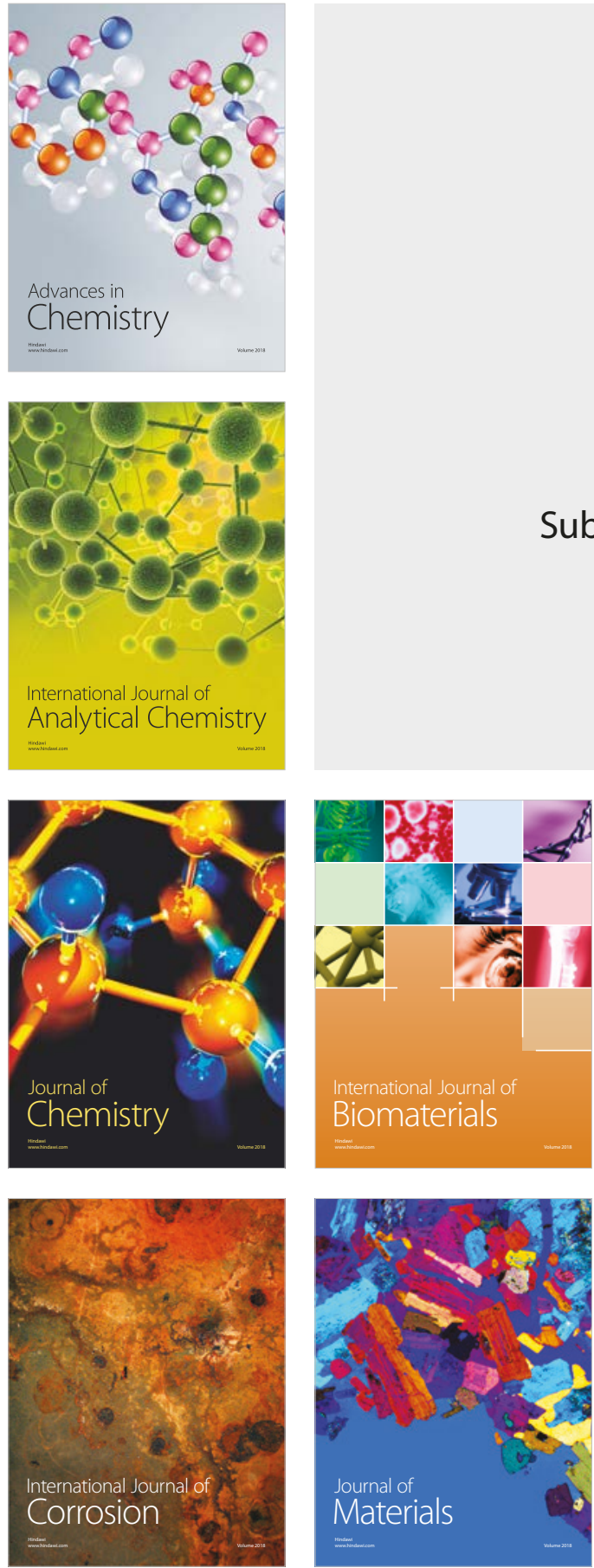

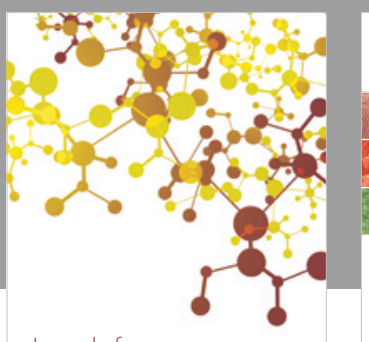

Journal of

Applied Chemistry
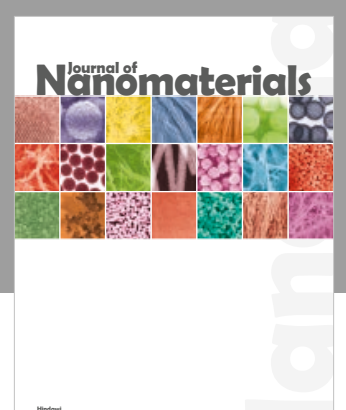

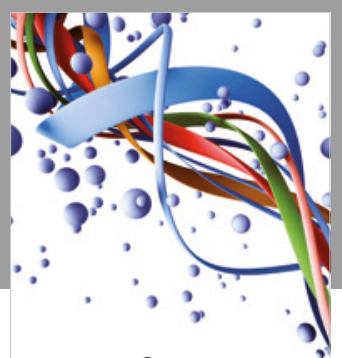

Scientifica

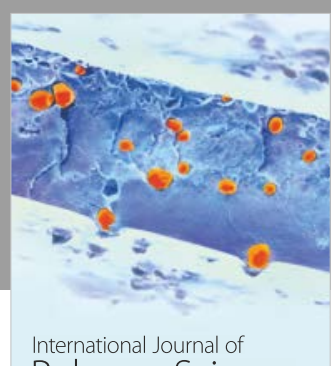

Polymer Science

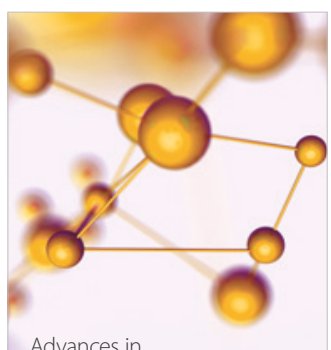

Physical Chemistry
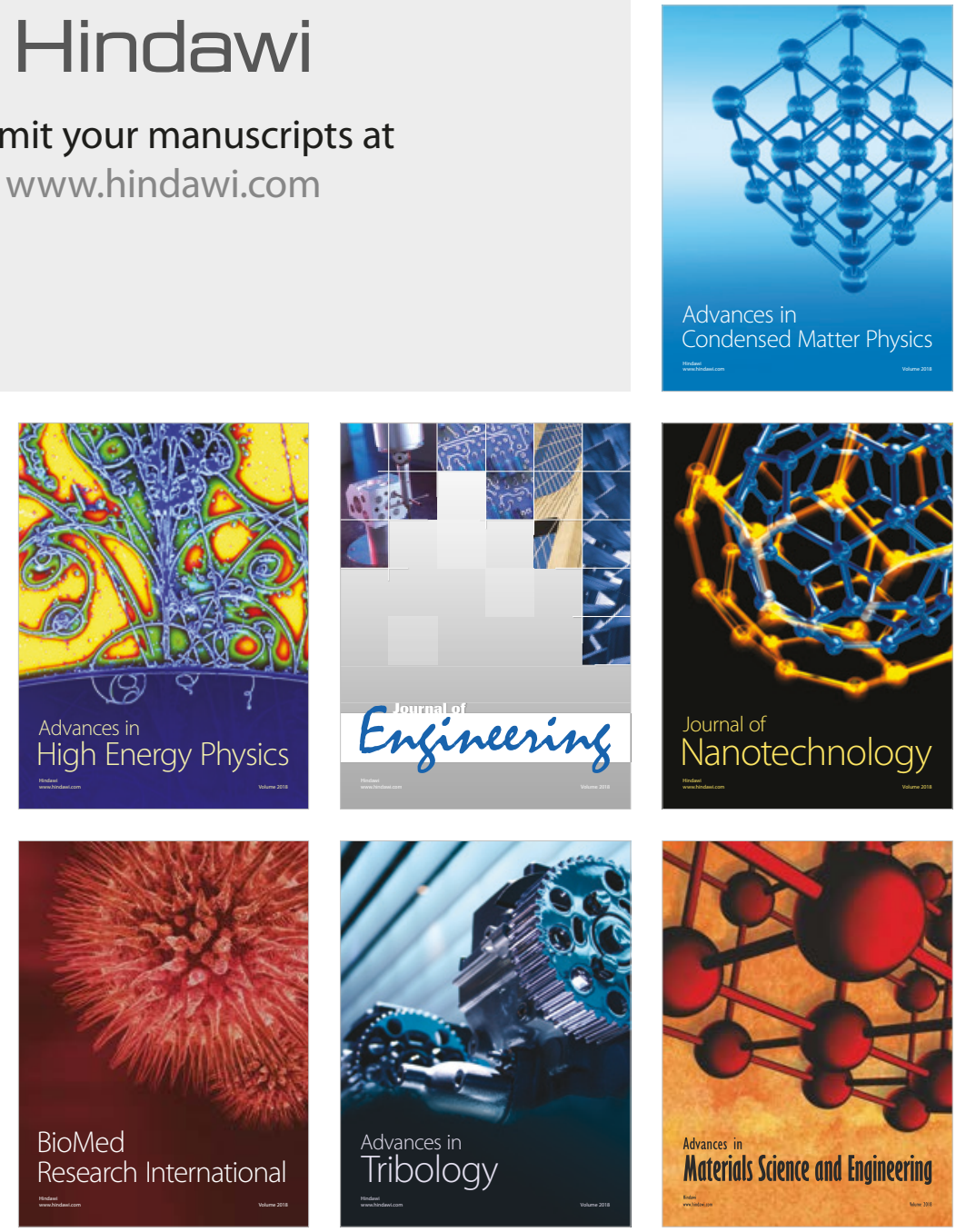